\title{
Ludwig Haberlandt - "Grandfather of the Pill"
}

The least-known character in the history of the Pill is Ludwig Haberlandt, professor of physiology at the University of Innsbruck. As early as 1919, he started on a pioneering series of crucial experiments (described in detail in this issue of Wiener klinische Wochenschrift by his granddaughter, Dr. Edda Haberlandt) on what he called "hormonal temporary sterilization" - work that was supported financially for years by the Rockefeller Foundation.

In publications over the course of ten years, Haberlandt - invariably using the first person singular (because he essentially worked alone), so strikingly different from the royal "we" of today's scientists - emphasized the obvious applicability of his animal experiments to human contraception. He fully recognized that the responsible factor was a constituent of the corpus luteum, although at that time the pure active principle, progesterone, had neither been isolated nor yet synthesized.

In 1931, in a remarkable book, Die hormonale Sterilisierung des weiblichen Organismus, of less than 15,000 words that hardly any reproductive biologist now living seems to have read, Haberlandt outlined in uncanny detail the contraceptive revolution of some thirty years later. $\mathrm{He}$ pointed out that oral administration would be the method of choice as well as the necessity for periodic withdrawal from the hormone to allow menses to occur. He called for the use of such contraception on clinical and eugenic grounds, arguing that it would enable parents to have the desired number of healthy children.

Objections by people like the sexologist van de Velde that too many women would take advantage of hormonal contraception was dismissed by Haberlandt with the argument that such preparations would require a

Correspondence: Carl Djerassi, Professor of Chemistry (emer.), Stanford University, Department of Chemistry, 333 Campus Drive, Mudd Building, Room 121, Stanford, CA 94305-5080, USA, E-mail: djerassi@stanford.edu physician's prescription and would not be made available over the counter. He ended his manifesto with a visionary claim: Unquestionably, practical application of the temporary hormonal sterilization in women would markedly contribute to the ideal in human society already enunciated a generation earlier by Sigmund Freud (1898). "Theoretically, one of the greatest triumphs of mankind would be the elevation of procreation into a voluntary and deliberate act."

As described by Dr. Edda Haberlandt, he had even invented a trade name, "Infecundin" for the oral contraceptive he had envisaged. Although the 47-year old Haberlandt tragically committed suicide in 1932, the name "Infecundin" survived. In 1966, it became the trade name of the first oral contraceptive produced in Hungary by the very same company Haberlandt had contacted 40 years earlier.

Within two years of his death, pure progesterone was isolated in no less than four laboratories in Germany, the US, and Switzerland; its chemical structure established by Karl Slotta (eventually, a Hitler refugee settling in Brazil); and its synthesis from the soyasterol stigmasterol accomplished. Had Haberlandt lived, there is no question that he would have pursued his dream of temporary hormonal sterilization in humans without resorting to glandular extracts. But even with pure progesterone, he could have shown only that ovulation can be inhibited by injection. For oral administration, he would have needed another steroid - not naturally occurring, but waiting to be synthesized - and that took twenty more years. Thus, nothing further happened, and Haberlandt's work fell into such oblivion that the next biologist to take it up, Gregory Pincus (who clearly should have known better), did not even feel obligated to cite Haberlandt among the 1459 references in his own opus magnum, The Control of Fertility (1965). Nor for that matter did Pincus's clinical collaborator, John Rock, whose book The Time has come (1963) quote any of Hab- 
erlandt's pioneering earlier research. Yet if there ever was a grandfather of the Pill, Ludwig Haberlandt above all others deserves that honor.

Much of what I say above comes from a memoir ${ }^{1}$ of mine written on the $50^{\text {th }}$ birthday of the first chemical synthesis of an orally active progestin, norethindrone, which we accomplished ${ }^{2}$ in the research laboratories of a minute Mexican pharmaceutical company, Syntex S.A. Within weeks of that synthesis on October 15, 1951, we had sent samples of this powerful, orally active progestin to various biologists: Roy Hertz (Bethesda, MD); Alexander Lipschütz (Santiago, Chile); Gregory Pincus

${ }^{1}$ C. Djerassi, This Man's Pill - Reflections on the 50 $0^{\text {th }}$ Birthday of the Pill, Oxford University Press, Oxford, 2001; This Man's Pill-Sex, Die Kunst und Unsterblichkeit, (German translation by UrsulaMaria Mössner) Haymon Verlag, Innsbruck, 2001.

2 C. Djerassi, L. Miramontes, G. Rosenkranz and F. Sondheimer, J. Am. Chem. Soc. 76, 4092 (1954) based on patent application by C. Djerassi, L. Miramontes, and G. Rosenkranz filed on November 22, 1951
(Shrewsbury, MA); Robert Greenblatt (Athens, GA); and Edward Tyler (Los Angeles). If he had not earlier committed suicide - in part for the virulent opposition to his work - Haberlandt would only have been in his middle sixties at the time and undoubtedly would have been the first recipient of our norethindrone. No doubt that with his motivation, he would have turned not only into the grandfather but also the father of the Pill. I find it tragic that posthumously, he has not only been ignored in the Anglo-Saxon scientific world but largely also in his home country. In my opinion, an appropriate step would be to issue an Austrian postage stamp with the image of the title page of his prophetic book which I reproduce in this editorial.

Carl Djerassi

\section{Conflict of Interest}

The authors declare that there is no conflict of interest. 